\title{
Coexistence of Spontaneous Bacterial Peritonitis and Spontaneous Bacterial Empyema Carries Poor Prognosis in Cirrhotic Patients with Ascites and Hydrothorax
}

\author{
Wagdy Abd El-Fattah Mohamed ${ }^{1}$, Nashaat M. Soliman ${ }^{2}$, Abdulrahman \\ Alduraywish ${ }^{3}$ Mahmoud Kamel Mansour $^{4}$, Mohamed Mosaad ${ }^{1}$, \\ Mostafa M. Ragheb ${ }^{1}$ \\ ${ }^{1}$ Chest Diseases and Tuberculosis Department, Faculty of Medicine, Suez Canal University, Egypt \\ ${ }^{2}$ Endemic and Infectious Diseases Department, Faculty of Medicine, Suez Canal University, Egypt. \\ ${ }^{3}$ Internal Medicine Department, Jouf University, Saudi Arabia. \\ ${ }^{4}$ Microbiology and Immunology Department, Faculty of Medicine, Suez Canal University, Egypt.
}

Corresponding Author Mohamed Mosaad, MD.

Mobile:

00201092304322

E mail:

mohmosad4@yahoo. com

Key words: liver cirrhosis, Hepatic hydrothorax, $S B P$, SBEM.
Background and study aim: Patients with decompensated cirrhosis suffer from serious sequelae including infections that may endanger life. The study aimed at determination of the incidence, outcomes and risk factors of spontaneous bacterial empyema (SBEM) among patients with cirrhotic ascites and hydrothorax.

Patients and Methods: This study included 50 patients subjected to clinical, imaging and biochemical workup including diagnostic tapping of ascitic and pleural fluid to diagnose spontaneous bacterial peritonitis (SBP) by cellular count and SBEM by cellular count and culture.

Results: There The mean age was 57.14 years and $52 \%$ were males. SBP was found in 25 cases $(50 \%)$; alone in 15 and

\section{INTRODUCTION}

Cirrhosis is the end result of chronic hepatitis complicating $\mathrm{HBV}, \mathrm{HCV}$, alcohol intake or non alcoholic steatohepatitis. Early cirrhosis is usually asymptomatic till decompensation occurs. During this stage, patients suffer from serious sequelae and complications including hepatocellular carcinoma, hepatic encephalopathy, gastrointestinal hemorrhage, renal failure and infections. The occurrence of these complications could not be predicted and may lead to further deterioration of liver function and endanger life $[1,2]$. with concomitant SBEM in 10. Only 7 (14\%) had positive culture of the pleural fluid including five gram positive bacteria. Patients SBP and SBP/SBEM had significantly higher mean age, higher median TLC, and corrected PMN in pleural fluid compared to patients with no infection. The infection group stayed a significantly more duration in hospital. All the four deaths occurred in the infection group, three with SBP/SBEM and one with SBP. By multivariate logistic regression analysis, pleural fluid TLC and corrected PMN and duration of hospital stay were significant independent predictors of SBEM.

Conclusion: SBEM is a common sequel of hydrothorax in patients with cirrhotic ascites and its coexistence with SBP leads to higher morbidity and mortality.

During the few two decades, improvement in treatment of $\mathrm{HBV}$ and $\mathrm{HCV}$, management of portal hypertension, hepatocellular carcinoma and liver transplantation are associated with better quality of life and longer survival. The altered immune state associated with decompensated cirrhosis predisposes to different types of infection e.g. SBP, SBEM, spontaneous bacteremia, health-care related infections, and infections from uncommon pathogens including fungi. Severe infection could be the underlying cause of acute decompensation or acute on chronic liver failure [3]. 
Hepatic hydrothorax is defined as the presence of significant amount of pleural fluid that occurs in $5-12 \%$ of cirrhotic patients with portal hypertension [4]. The condition is frequently associated with ascites leading to respiratory distress. Spontaneous bacterial empyema (SBEM) is the term used to describe spontaneous infection of the pleural fluid in cases with hepatic hydrothorax [5]. The probability of SBEM increases with severe decompensation. In addition, spontaneous bacterial peritonitis, (SBP) is a predictive factor of SBEM [6]. This serious complication is usually associated to increased morbidity and mortality [7].

The diagnosis of SBEM is made in a cirrhotic patient with hydrothorax when the pleural fluid shows a polymorphonuclear (PMN) cell count $>500$ cells $/ \mathrm{mm}^{3}$ or positive culture with PMN cell count $>250$ cells $/ \mathrm{mm} 3$ with the exclusion of a parapneumonic effusion [8].

However, SBEM is usually underestimated because examination of the pleural fluid is not done routinely. The aim of the present study was to assess frequency, patterns and risks of spontaneous bacterial empyema among patients admitted to hospital with cirrhotic ascites and hydrothorax so as to improve diagnosis and care and decrease mortality.

\section{PATIENTS AND METHODS}

This prospective follow up study included 50 adult patients admitted with ascites and pleural effusion. All had evidence of decompensated cirrhosis with or without clinical manifestations of infection. However, the study excluded patients with other causes of pleural fluid collection or infection (as pneumonia, tuberculosis or malignancy), patients given antimicrobials on admission or underwent tapping of ascetic or pleural fluid within the last week before admission.

During the study, all patients were subjected to the following:

A: Sociodemographic data, history and physical examination.

B: Baseline laboratory tests including complete blood picture, erythrocyte sedimentation rate, liver function tests (including ALT, AST, total proteins, serum albumin, globulin, total and direct bilirubin and prothrombin time), serum creatinine and fasting blood sugar.
$\mathrm{C}$ : Imaging by $\mathrm{X}$-ray chest and pelvi-abdominal ultrasonography X-ray chest

D- Laboratory tests for diagnosing of SBP and SBEM:

Diagnostic aspiration of ascitic and pleural fluids was done under complete aseptic conditions. The fluid was examined for the following: a) Physical examination including colour and aspect. B) Cell count: The fluid sample was anticoagulated by EDTA and examined for total and differential leukocytic count and red blood cell count (RBC). In the presence of RBCs, PMN cell count was corrected by subtracting one PMN cell from the absolute count for every 250 red cells.

c) Biochemical tests: This included total proteins, LDH and glucose levels in ascitic and pleural fluids.

d) Ascitic fluid culture: This was done by direct inoculation of $10 \mathrm{cc}$ pleural fluid in $80 \mathrm{ml}$ blood culture bottles (diphasic, Oxoid signal blood culture system medium, Oxoid limited; England) at the bed side. Blood culture bottles were incubated in aerobic conditions at 37C for 7-10 days. Growth was observed and subcultures were done at first day and every other day on MacConkey and blood agars and incubated at 5$10 \%$ CO2. Positive cultures were identified by microscopic examination for unstained and Gram stained preparations and by a short set of biochemical reactions.

Meanwhile, cytological examination of the fluid samples for malignant cells and Ziehl-Neelsen staining for acid fast bacilli were done only in case of clinical or laboratory suspicion.

The criteria of diagnosis of SBEM relied upon an absolute PMN cell count $>500 / \mathrm{cmm}$ with negative culture or $>250 / \mathrm{mm}^{3}$ with positive culture established diagnosis in absence of another etiology explain infection effusion (4) However, the diagnosis of SBP was made by an absolute PMN cell count of $500 / \mathrm{mm}^{3}$ in the ascitic fluid without culture. In addition, LDH, glucose and total protein in ascites or pleural fluids were done to differentiate between the nature of samples taken from ascites or hydrothorax, whether transudate or exudate.

\section{Statistical analysis:}

The collected data were managed by SPSSversion 17 program of statistical analysis. Continuous data were described as range, mean and standard deviation and qualitative data were 
summarized by frequencies and percentages. In analytic data, Chi square test was used to detect the difference between qualitative data, while Student $t$ test was used to detect the difference between continuous data. A p-value $<0.05$ was considered statistically significant.

\section{RESULTS}

\section{Descriptive data:}

From January 2011 to August 2011, 50 adult patients with cirrhotic ascites and hydrothorax were included; 26 males and 24 females. Their age ranged 43-73 years. Of all, 22 (44\%) were current smokers including two with history of alcohol intake. Of 50 patients, infection with HBV and HCV were the underlying etiology of liver disease in 1 and 37 respectively, schistosomal liver disease in 11 patients; comorbid with $\mathrm{HCV}$ in 5 and comorbid with $\mathrm{HBV}$ in one. In one patient, the etiology was not known. The cirrhotic patients were classified as Child C in $29(58 \%)$ and Child B in $21(42 \%)$. Comorbid illness was reported in 22 (44\%); being diabetes mellitus in 7 , hypertension in 4 , diabetes and hypertension in 7 and other comorbidity in 4 . History of previous tapping of ascites and/or pleural effusion was recalled in 23 (46\%). Clinically, the most frequent presenting manifestations on admission were fever $(60 \%)$ and abdominal tenderness (62\%) and less commonly dyspnea (38\%). Pleural effusion was right sided in 38, left sided in 9 and bilateral in 3. Most of the effusions were moderate (29/50), while massive and mild effusions were found in 12 and 9 patients.

Laboratory results showed anemia in $90 \%$ of patients, leukopenia in $18 \%$, leukocytosis in $12 \%$ and $86 \%$ had thrombocytopenia. Of all, $72 \%$ had prolonged INR. Serum creatinine ranged 0.5-6.2 $\mathrm{mg} / \mathrm{dl}$, $($ mean $=1.6 \pm 1.26)$. Impaired kidney function was present in 17 (table 1).

Diagnosis of SBP was made in $25(50 \%)$ patients and SBEM in 10 all had concomitant SBP. In the latter group, hydrothorax was right sided in 7 , left sided in one and bilateral in 2 . The workup revealed positive bacterial culture of the pleural fluid in $7(14 \%)$ cases. The isolated pathogens were gram positive in five $(71.43 \%)$, and gram negative in two. Patients stayed in hospital for 5 to 25 days (mean=12.6 \pm 5.2 ) and death occurred in $4(16 \%)$ patients with infection.

\section{Comparative data:}

The mean age of patients with infection was significantly higher compared to patients without $(59.5 \pm 9.3,61.3 \pm 9.2$ and $54.04 \pm 6.6$ respectively for SBP/SBEM, SBP and no infection, $\mathrm{p}=0.03$ ). The frequency of Child $\mathrm{C}$ was significantly higher in patients with SBP, SBP/SBEM $(60 \%$ and $90 \%$ respectively) compared to $44 \%$ in patients without $(\mathrm{p}=0.04)$. Fever and abdominal tenderness were significantly more frequent in patients with SBP $(86.7 \%$ and $80 \%)$ and SBP/SBEM (90\% and $90 \%)$ compared to patients without $(32 \%$ and $40 \%, \mathrm{p}=0.003)$. Meanwhile, the difference between the three subgroups regarding the frequency of smoking, previous tapping, comorbidity and culture positivity of the pleural fluid showed no statistically significance. The bacteria isolated from the pleural fluid were Staphylococcus aureus, diphtheroid and pseudomonas in 3 patients (30\%) with SBEM with SBP, Staphylococcus aureus and Staphylococcus epidermidis in 2 (13.3\%) patients with lone and $\mathrm{S}$. aureus and pseudomonas in 2 (8\%) of 25 patients with normal PMN cell count. The mean duration of hospital stay was significantly longer in patients with lone SBP and SBP/SBEM $(14.4 \pm 4.4$ and $16.8 \pm 4.2$ respectively) compared to patients without $(9.9 \pm$ 4.5, $\mathrm{P}=0.001)$. Mortality occurred in 3 of 10 patients with SBP/SBEM, one of 15 with SBP and none in patients without infection (table 2).

In 9 of 10 patients with SBEM. the absolute and corrected PMN cell counts were $>500 / \mathrm{mm}^{3}$ in the pleural fluid samples including two with positive culture. The remaining one had absolute and corrected PMN cell counts $>450 / \mathrm{mm}^{3}$ with positive culture.

The median values of TLC, absolute PMN and corrected PMN extracted from the pleural and ascitic fluid were highest in patients with SBP/SBEM followed by patients with SBP and least in patients without infection $(\mathrm{p}<0.001)$. (Table 3).

The Best fitting multiple logistic regression model revealed that TLC count and corrected $\mathrm{PMN}$ in pleural fluid and duration of hospital stay were significant predictors for occurrence of spontaneous bacterial empyema in patients with cirrhotic ascites and hydrothorax (table 4).

By ROC curve analysis, at a cut-off of $500 / \mathrm{mm}^{3}$ of TLC count in pleural fluid, diagnosis of 
SBEM can be made with a sensitivity of $100 \%$ (95\% CI: $69.15-100.00 \%$ ), specificity of $72.5 \%$ (95\% CI: $56.11-85.40 \%$ ), positive predicated value of $47.62 \%$ (95\% CI: 35.47-60.06\%) and negative predicated value of $100 \%$. While, at a cut-off of $440 / \mathrm{mm}^{3}$ of corrected PMN count in pleural fluid, diagnosis of SBEM can be made with a sensitivity of $100 \%$ (95\% CI: 69.15\%$100 \%$ ), specificity of $95 \%$ (95\% CI: $83-99.4$ ), positive predicated value of $83.3 \%$ (95\% CI: $56.43 \%$ to $95.07 \%)$, and negative predicated value of $100 \%$ (Graph 1 and 2).

Table (1): Characteristics of 50 patients with hepatic ascites and hydrothorax.

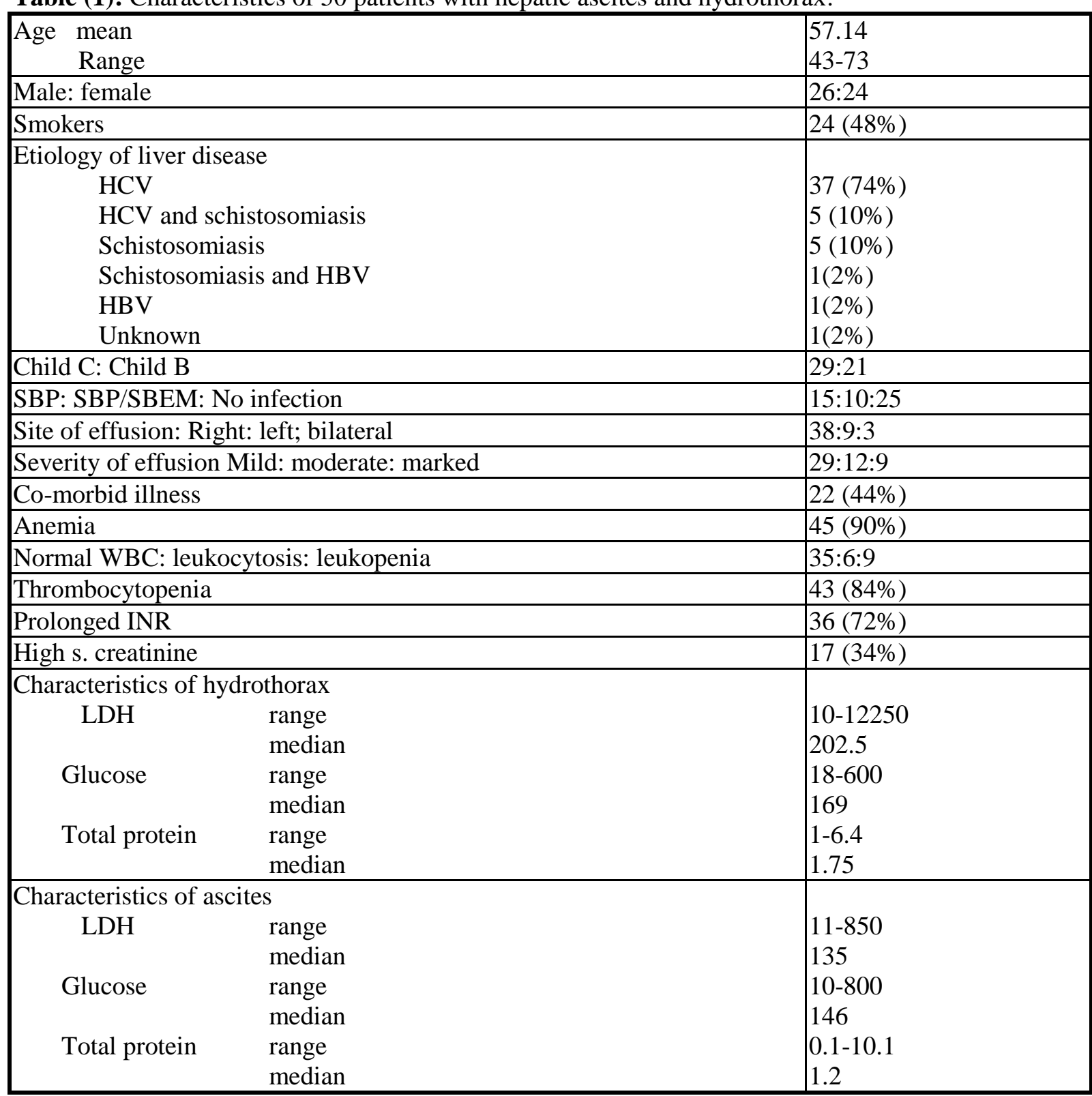


Table (2): Patients' characteristics and outcomes of hospitalization among three groups of patients.

\begin{tabular}{|c|c|c|c|c|c|}
\hline & & $\begin{array}{c}\text { SBP } \\
(n=15)\end{array}$ & $\begin{array}{c}\text { SBP and SBEM } \\
(n=10)\end{array}$ & $\begin{array}{l}\text { No infection } \\
(n=25)\end{array}$ & p-value \\
\hline \multicolumn{2}{|l|}{ Mean age } & $59.5 \pm 9.3$ & $61.3 \pm 9.2$ & $54.04 \pm 6.6 \#$ & $0.03 *$ \\
\hline \multicolumn{2}{|c|}{ Current smoking } & $8(53.3 \%)$ & $7(70 \%)$ & $9(36 \%)$ & 0.6 \\
\hline \multicolumn{2}{|c|}{ History of tapping } & $7(46.7 \%)$ & $6(60 \%)$ & $10(40 \%)$ & 0.6 \\
\hline \multicolumn{2}{|c|}{ Co-morbidity } & $9(60 \%)$ & $6(40 \%)$ & $9(36 \%)$ & 0.6 \\
\hline \multicolumn{2}{|c|}{ Fever } & $13(86.7 \%)$ & $9(90 \%)$ & $8(32 \%) \#$ & $0.003 *$ \\
\hline \multicolumn{2}{|c|}{ Abdominal tenderness } & $12(80 \%)$ & $9(90 \%)$ & $10(40 \%) \#$ & $0.005^{*}$ \\
\hline \multicolumn{2}{|c|}{ Positive Pleural fluid culture } & $2(13.3 \%)$ & $3(30 \%)$ & $2(8 \%)$ & $\mathrm{NA}^{* *}$ \\
\hline \multirow{2}{*}{ Child class } & Class B & $6(40 \%)$ & $1(10 \%)$ & $14(56 \%) \#$ & \multirow{2}{*}{$0.04^{*}$} \\
\hline & Class C & $9(60 \%)$ & $9(90 \%)$ & $11(44 \%)$ & \\
\hline \multicolumn{2}{|c|}{ Mortality rate } & $1(6.7 \%)$ & $3(30 \%)$ & $0(0 \%)$ & NA** \\
\hline \multicolumn{2}{|c|}{$\begin{array}{l}\text { Mean duration of hospital stay } \\
\text { (Days) }\end{array}$} & $14.4 \pm 4.4$ & $16.8 \pm 4.2$ & $9.9 \pm 4.5 \#$ & $0.001 *$ \\
\hline
\end{tabular}

NS: no statistically significant difference

\#Statistically significant difference versus other two groups (post hoc test)

*Statistically significant difference between three groups (ANOVA test)

** NA: not applicable

Table (3): Cellular findings in the pleural and ascetic fluids in the three groups.

\begin{tabular}{|ll|c|c|c|c|}
\hline & & $\begin{array}{c}\text { SBP } \\
(\mathbf{n = 1 5})\end{array}$ & $\begin{array}{c}\text { SBP and SBEM } \\
(\mathbf{n = 1 0})\end{array}$ & $\begin{array}{c}\text { Neither SBP nor } \\
\text { SBEM (n=25) }\end{array}$ & p-value \\
\hline Pleural fluid TLC & range & $400-900$ & $600-3000$ & $100-900$ & $<0.0001$ \\
& median & 500 & 800 & 250 & \\
\hline Pleural fluid Absolute PMN & range & $180-783$ & $450-2700$ & $25-810$ & $<0.0001$ \\
& median & 272 & 692 & 118.5 & \\
\hline Pleural fluid Corrected PMN & range & $180-480$ & $450-2410$ & $25-468$ & $<0.0001$ \\
& median & 264 & 692 & 117 & \\
\hline Ascitic fluid TLC & range & $400-11600$ & $253-8500$ & $100-500$ & $<0.0001$ \\
& median & 600 & 1100 & 200 & \\
\hline Ascitic fluid Absolute PMN & range & $319-8468$ & $374-21505$ & $18-420$ & $<0.0001$ \\
& median & 396 & 4081 & 126 & \\
\hline Ascitic fluid Corrected PMN & range & $252-8468$ & $374-215-5$ & $19-153$ & $<0.0001$ \\
& median & 432 & 2607.5 & 90 & \\
\hline
\end{tabular}

Table (4): Multiple regression analysis of predictors of SBEM.

\begin{tabular}{|l|c|c|c|c|c|}
\hline & Coefficient & Std. error & $\mathbf{t}$ & $\begin{array}{c}\text { Odds } \\
\text { ratio }\end{array}$ & p-value \\
\hline Constant & -0.05 & & & & \\
\hline $\begin{array}{l}\text { TLC in pleural fluid } \\
\text { Reference value: < 500) }\end{array}$ & 0.002 & 0.00037 & 5.48 & 1.9 & $0.0001^{*}$ \\
\hline $\begin{array}{l}\text { Corrected PMN in pleural fluid } \\
\text { (reference value: <440) }\end{array}$ & 0.01 & 0.00688 & 2.12 & 1.6 & $0.005^{*}$ \\
\hline $\begin{array}{l}\text { Duration of hospital stay } \\
\text { Reference value: 16 day) }\end{array}$ & -0.001 & 0.0032 & -3.74 & 1.2 & $0.03^{*}$ \\
\hline
\end{tabular}




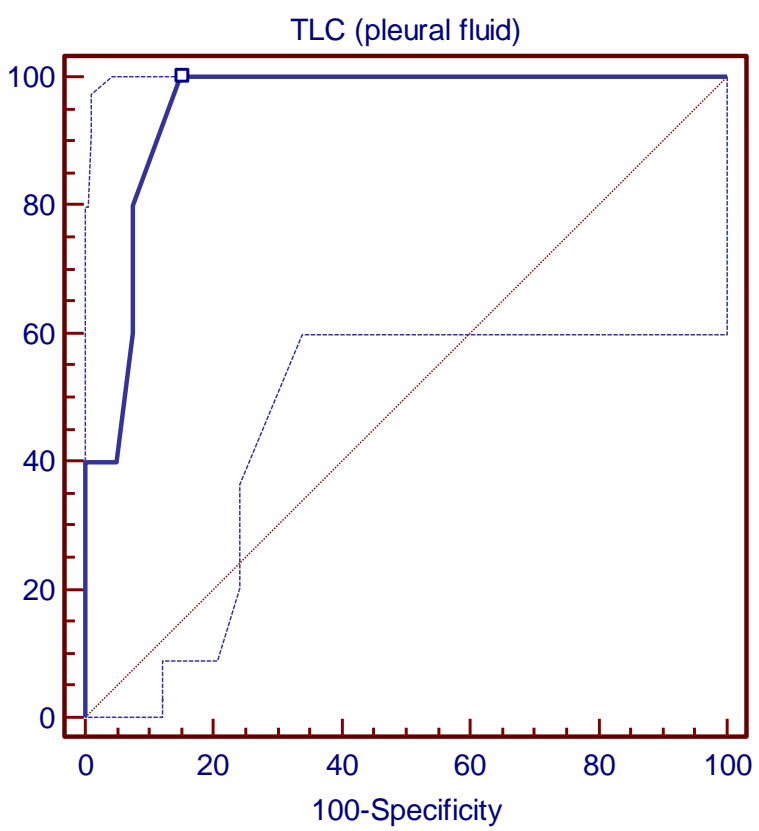

Graph (1): ROC curve analysis of TLC in pleural fluid that can detect SBEM:

At a cut-off of 500/mm3 of TLC count in pleural fluid, diagnosis of SBEM can be made with a sensitivity of $100 \%$ (95\% CI: 69.15-100.00\%), specificity of $72.5 \%$ (95\% CI: 56.11-85.40\%), positive predicated value of $47.62 \%$ (95\% CI: $35.47-60.06 \%$ ) and negative predicated value of $100 \%$.

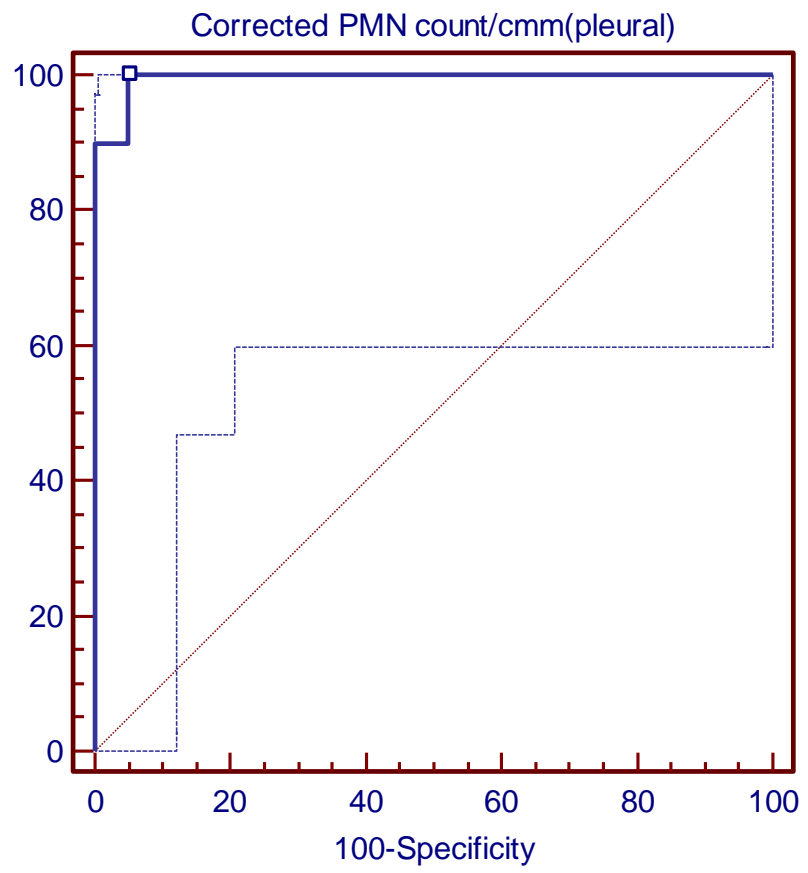

Graph (2): ROC curve analysis of corrected PMN in pleural fluid that can detect SBEM:

At a cut-off of $440 / \mathrm{mm} 3$ of corrected PMN count in pleural fluid, diagnosis of SBEM can be made with a sensitivity of $100 \%$ (95\% CI: $69.15 \%-100 \%$ ), specificity of $95 \%$ (95\% CI: $83-99.4$ ), positive predicated value of $83.3 \%$ (95\% CI: $56.43 \%$ to $95.07 \%$ ), and negative predicated value of $100 \%$. 


\section{DISCUSSION}

This study aimed to determine the incidence of SBEM in adult patients admitted with cirrhotic ascites and hydrothorax. In the present study, hydrothorax was predominantly right sided and in patients with SBEM, effusion was right sided in 70\%. This pattern has been also reported many studies $[\mathbf{9 , 1 0 , 1 1 ]}$. The incidence of infection in this cohort was 50\%; all had SBP alone in 15 (30\%) patients and with concomitant SBEM in $10(20 \%)$. In Sharkia, Emam and colleagues reported SBP in $33.5 \%$, SBEM in $14.3 \%$ and $63 \%$ of patients with SBEM had SBP while in Menofia, the corresponding incidences were higher $(68.6 \%, 51.4 \%$ and $86.1 \%$ respectively). In Upper Egypt, the incidence of SBEM was 26.2\% [11,12,13] The high incidence of SBP compared to SBEM in these Egyptian series, contradicts with a study that reported a similar incidence of SBP and SBEM in patients with cirrhosis in Spain [14]. The variation in the incidence of SBEM could be explained by difference in criteria or different methods of diagnosis [11] or the severity of decompensation. Although it is difficult to determine the portal of entry of the causative pathogens of SBEM, the coexistence of SBP in all our cases with SBEM, could be due to extension from the infected peritoneal fluid [15]. The high incidence of SBP in this study (50\%) is higher than $33.4 \%$ and $20.2 \%$ in two series of cirrhotic patients with ascites only in the same hospital studied in 1997 and 2006 respectively. [16,17]. Coexistence of hydrothorax with ascites could reflect severe decompensation which is a risk factor for spontaneous bacterial peritonitis.

In this study, fever and abdominal tenderness were cardinal manifestations in the majority patients with SBP or SBP/SBEM. However, dyspnea was less frequently encountered and its frequency showed no significant difference between the studied subgroups. This finding weakens the importance of dyspnea in diagnosis of SBEM in our patients while other studies suggested SBEM in patients with hydrothorax with dyspnea and fever [18,19]. Other causes of dyspnea in such patients may include ascites, pulmonary hypertension, anemia, cardiomyopathy or hepatopulmonary syndrome

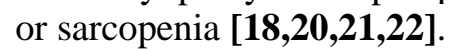

This study reveals poor outcome of hospitalization in patients with infection in term of increase duration of hospitalization, high rate of morbidity and mortality. Patients with concomitant SBP and SBEM had higher rate of mortality $(30 \%)$ compared to $6.7 \%$ of patients with SBP alone and none in patients without. Impaired renal function and hepatic encephalopathy were also more frequent in infected patients (44\% and 16\%) compared to patients without infection (24\% and $12 \%)$. The relation of the severity of decompensation with occurrence of infection and mortality was also evident in this study. All the four deceased patients were Child C, 3 with SBP/SBEM and one with SBP alone. The association of severe decompensation with SBEM related mortality reported by others $[4,11,13,19,23]$.

In a large cohort of decompensated cirrhosis with various types of infection, the 28-day-mortality rate was high particularly when associated with multidrug resistant pathogens $[\mathbf{2 4 , 2 5}$. Infection in cirrhotic patients were reported to be a leading cause of acute decompensation and hospitalization and recent reports considered infection as one of the manifestations of decompensation that carried up to 4 fold increase in mortality $[25,26]$. The negative effect of spontaneous bacterial infections on morbidity and mortality of patients with decompensated cirrhosis $[\mathbf{2 6 , 2 7 , 2 8 ]}$ is complicated by their tendency for recurrence $[29,30]$.

In this study, bacterial culture resulted in 7 (14\%) isolates from 50 pleural fluid samples. Culture was positive in only 3 cases of SBEM, while the other 4 had no clinical or cellular evidence of empyema. The significance of culture positive pleural fluid in these patients is difficult to explain. There is no enough data referring to this condition in the pleural fluid in cirrhotic patients. However, this condition could resemble bacterascites. Pelletier and colleagues considered the presence of bacteria in ascites of asymptomatic patients with normal PMN cell count as a transient phase and they reported rare progression to SBP and no need for antimicrobial therapy [31]. However, in a recent study, Oey and colleagues reported persistence of the bacteria or progression to SBP if left untreated [32].

The pathogens were gram positive in $5(71.4 \%)$ and 2 gram negative pseudomonas bacteria. The low yield of bacterial culture in this study is comparable to $9.3 \%$ reported by Emam and colleagues. Repeated administration of antimicrobials could be the underlying 
explanation. However, predominance of gram positive bacteria, in this study, contradicts with other reports from Egypt where gram negative bacteria predominated $[\mathbf{1 1 , 1 2 ]}$. In our hospital, the frequency of gram positive bacteria isolated from infected ascites increased 4 times from $7.8 \%$ in 1997 to $30.1 \%$ in 2006. The same observation was reported by Guo and colleagues. The practice of prescribing antimicrobial prophylaxis for patients with ascites could be the underlying factor for this changing pattern of pathogens that includes quinolone resistant or gram positive bacteria $[33,34,35,36]$.

The criteria of diagnosis of SBEM, in the current study, relied upon an absolute PMN cell count $>500 / \mathrm{mm}^{3}$ with negative culture or $>250 / \mathrm{mm}^{3}$ with positive culture established diagnosis in absence of another etiology explain infection effusion [4]. Our study emphasized the importance of TLC and corrected PMN cells, extracted from pleural effusion, in diagnosis of SBEM. By ROC curve analysis, their diagnostic values were comparable. Although, the corrected PMNC at a cut-off of $440 / \mathrm{mm}^{3}$ has a higher specificity and positive predictive value compared to TLC at a cut-off value of $500 / \mathrm{mm}^{3}$, this finding could not be generalized due to small number of cases with SBEM.

In all the 10 cases of SBEM, the corrected PMN cells were much higher than $250 / \mathrm{mm}^{3}$ even in culture positive cases. The counts were higher than $500 / \mathrm{mm}^{3}$ in 9 of 10 patients, two of them were culture positive and the remaining one had a count of 450 with positive culture. In this study, TLC count (reference value of 500) and corrected PMN (reference value of 440) in pleural fluid and duration of hospital stay (reference value of 16 days) were significant predictors for occurrence of SBEM in patients with cirrhosis. This finding emphasized the importance of repeat measurement of TLC and corrected PMN cell counts for predicting or diagnosis of early SBEM. Meanwhile, serial cellular assessment in symptomatic cases with spontaneous bacterial infections could predict prognosis. In one study, follow up of cases with SBP revealed a high baseline PMNCs $\left(\geq 600 / \mathrm{mm}^{3}\right)$ and/or persistently high PMNC counts were predictors of mortality and that its serial decline implied a good prognosis [37].

\section{Limitations of the study:}

The small number of patients with SBEM as well as its coexistence with SBP, could not enable the authors to describe its natural course. Meanwhile, it is not exactly known whether the poor outcome reported is due to combination of SBEM and SBP or due to SBEM alone. Another limitation was the low rate of positive culture despite the use of blood culture bottle and appropriate media. However, the low yield of culture could be due to prior use of antimicrobial particularly that with long half-life as levofloxacin for treatment or prophylaxis to prevent SBP. Third, as the main objective of the study is diagnosis of SBEM, no culture was done for samples of ascites and diagnosis of SBP depended largely on absolute PMN cell count $>500 / \mathrm{mm}^{3}$.

\section{CONCLUSION}

Spontaneous bacterial empyema is not uncommon in cirrhotic patients with ascites and hydrothorax. This type of infection carries high mortality and morbidity rates and increases the cost of health care particularly if coexists with SBP.

\section{Recommendation:}

In patients with cirrhotic ascites and hydrothorax, early diagnosis of spontaneous bacterial infection in both serosal fluids is important to avoid deterioration of liver function and decrease mortality as that encountered in patients with coexistent SBP and SBEM. Due to the unfavorable outcomes of SBEM particularly if associated with SBP, daily or weekly doses of antimicrobials could prevent recurrence and save lives and cost. Furthermore, there is an urgent need to study the significance of bacteria in pleural fluid in asymptomatic cirrhotic patients with normal PMN cell count.

Funding: This study is self-funded.

Conflict of interest: The authors declare that they have no conflicts of interest. 


\section{Ethical considrations:}

The study was approved by the Faculty of Medicine Ethical Committee. The aim, and benefits of the study were explained individually to each patient and after approval, an informed consent was obtained from each participant.

\section{REFERENCES}

1. Patel AA, Walling AM, Ricks-Oddie J, May FP, Saab S, Wenger N. Palliative Care and Health Care Utilization for Patients with End-Stage Liver Disease at the End of Life. Clin Gastroenterol Hepatol 2017; 15: 1612-19. doi:10.1016/j.cgh.2017.01.030 pmid:28179192

2. D'Amico G, Garcia-Tsao G, Pagliaro L. Natural history and prognostic indicators of survival in cirrhosis: a systematic review of 118 studies. $J$ Hepatol 2006; 44(1):217-31.

3. Bunchorntavaku C, Chamroonku N, Chavalitdhamrong D. Bacterial infections in cirrhosis: A critical review and practical guidance. World J Hepatol 2016;, 8(6): 307-321. doi: 10.4254/wjh.v8.i6.307

4. Garcia N Jr, Mihas AA. Hepatic hydrothorax: Pathophysiology, diagnosis and management. $J$ Clin Gastroenterol 2004; 38:52-8.

5. Allam NA. Spontaneous bacterial empyema in liver cirrhosis: an underdiagnosed pleural complication, Saudi Journal of Gastroentrol; 14 (1): 43.

6. Sese E, Xiol X, Castellote J, Rodriguez-Farinas E, Tremosa G. Low complement levels and opsonic activity in hepatic hydrothorax: Its relationship with spontaneous bacterial empyema. J Clin Gastroenterol 2003, 36: 75-7.

7. EI-Said M.G. EL-Badrawy, and Nasr E. Mohammed. Doxycycline Pleurodesis in Hepatic Hydrothorax. JIMA 2006; 38: 56.

8. Abbasi A, Bhutto AR, Alam MT, Aurangzaib M, Masroor M. Frequency of Hepatic Hydrothorax and its Association with Child Pugh Class in Liver Cirrhosis Patients. J Coll Physicians Surg Pak 2016; 26(7):566-9. doi: 2371.

9. Lazardis KN, Frank JW, Krowka MJ, Kamath PS. Hepatic hydrothorax: pathogenesis, diagnosis, and management. Am J Med 1999; 107: 262-267.

10. Alagiakrishnan K, Patel PJ. Left-sided hepatic hydrothorax with ascites. Int J Clin Pract 1999; 53(3):225-6 .

11. Emam M, Galal S, Darwish E. Study of Frequency of Spontaneous Bacterial Empyema in Cirrhotic Patients With Hepatic Hydrothorax. J Gastroenterol and Hepatol Research 2015; 4 (4).
12. Mohamed A, Atef M, Alsebaey A, Musa Elhabshy M, Salama M. Combined spontaneous bacterial empyema and peritonitis in cirrhotic patients with ascites and hepatic hydrothorax. Arab J Gastroenterol 2017.

13. Makhlouf HA, Morsy KH, Eldin EN, Khairy M. Spontaneous bacterial empyema in patients with liver cirrhosis in Upper Egypt: prevalence and causative organisms. Hepatol Int 2013; 7: 274279

14. Sese E, Xiol X, Castellote J, Rodriguez E, Tremosa G. Low complement levels and opsonic activity in hepatic hydrothorax. $\mathrm{J}$ Clin Gastroenterol 2003, 36: 75-77.

15. Baylor PA, Bobba VV, Ginn PD, Gitlin N, and Gitlin N. Recurrent spontaneous infected pleural effusion in a patient with alcoholic cirrhosis, hepatic hydrothorax, and ascites. West J Med 1988; 149: 216-217

16. Attia F. The prevalence and risk factors of spontaneous bacterial peritonitis in patients with ascites due to chronic liver disease. Thesis for M.Sc. (Internal Medicine), Faculty of medicine, Suez Canal University, 1997.

17. Salem AG. The prevalence and causative bacteria of spontaneous bacterial peritonitis in patients with ascites due to cirrhosis". Thesis for M.Sc. (Internal Medicine), Faculty of medicine, Suez Canal University, 2007.

18. Zetterman RK (2013). Pulmonary Complications of Cirrhosis. https://www.medscape.com/ viewarticle/777530_2 (Accessed on 9.11.2019)

19. Kwo PY. Shortness of breath in the patient with chronic liver disease. Clin Liver Dis 2012; 16(2):321-9. doi: 10.1016/j.cld.2012.03.007.

20. Xiol X, Castellvi JM, Guardiola J, Sese E, Castellote J, Perello A, et al. Spontaneous bacterial empyema in cirrhotic patients: a prospective study. Hepatology 1996; 23: 719723.

21. Hourani JM, Bellamy PE, Tashkin DP, Batra P, Simmons MS. Pulmonary dysfunction in advanced liver disease: frequent occurrence of an abnormal diffusing capacity. Am J Med 1991; 90(6):693-700.

22. Kaltsakas G, Antoniou E, Palamidas AF, Gennimata SA, Paraskeva P, Smyrnis A, et al. Dyspnea and respiratory muscle strength in endstage liver disease. World J Hepatol 2013; 5(2):56-63.

23. Tu CY, Chen CH. Spontaneous bacterial empyema. Curr Opin Pulm Med 2012; 18(4):3558. doi:

24. Piano S, Singh V, Caraceni P, Maiwall R, Alessandria C, Fernandez J, et al. Epidemiology and Effects of Bacterial Infections in Patients with Cirrhosis Worldwide. Gastroenterology 2019; 156 (5):1368-1380. 
25. Gupta T, Lochan D, Verma N, Rathi S, Aqrawal S, Duseja A, et al. Prediction of 28-day mortality in acute decompensation of cirrhosis through the presence of multidrug-resistant infections at admission. Gastroenterol Hepatol 2019; doi: 10.1111/jgh.14788.

26. Arvaniti V, D'Amico G, Fede G, Manousou P, Tsochatzis E, Plequezuelo $\mathrm{M}$, et al. Infections in patients with cirrhosis increase mortality four-fold and should be used in determining prognosis. Gastroenterology 2010; 139: 12461256.

27. Runyon BA. Spontaneous bacterial peritonitis: an explosion of information. Hepatology 1988; 8(1):171-5

28. Titó L, Rimola A, Ginès P, Llach J, Arroyo V, Rodes $\mathrm{J}$, et al. Recurrence of spontaneous bacterial peritonitis in cirrhosis: frequency and predictive factors. Hepatology 1988; 8(1):27-31.

29. Baylor PA, Bobba VV, Ginn PD, and Gitlin N. Recurrent spontaneous infected pleural effusion in a patient with alcoholic cirrhosis, hepatic hydrothorax, and ascites. West J Med 1988; 149(2): 216-217.

30. Alonso JC. Pleural effusion in liver disease. Semin Respir Crit Care Med 2010; 31(6):698-705.

31. Pelletier G1, Lesur G, Ink O, Hagege H, Attali P, Buffet C, et al. Asymptomatic bacterascites: is it spontaneous bacterial peritonitis? Hepatology 1991; 14(1):112-5.
32. Oey RC, van Buuren HR, de Jong DM, Erler NS, de Man RA. Bacterascites: A study of clinical features, microbiological findings, and clinical significance. Liver Int 2018; 38(12):2199-2209.

33. Cholongitas E, Papatheodoridis GV, Lahanas A, Xanthaki A, Kontou-Kastellanou C, Archimandritis AJ, et al. increasing frequency of Gram-positive bacteria in spontaneous bacterial peritonitis. Liver Int 2005; 25 (1): 57- 61.

34. Almeida PRL, Camargo NS, Arenz M, Tovo CV, Galperim B, Behar P. Spontaneous bacterial peritonitis: impact of microbiological changes. Arq Gastroenterol 2007; 44(1):68-72 (English abstract).

35. Guo J, Shi J, Wang H, Chen H, Liu S, Li J, et al. Emerging Gram-positive bacteria and drug resistance in cirrhosis patients with spontaneous bacterial peritonitis: A retrospective study. Experimental and Therapeutic Medicine 2019; 17, 4568-4576.

36. Yan $\mathrm{K}$ and Garcia-Tsao G. Novel prevention strategies for bacterial infections in cirrhosis. Expert Opin Pharmacother 2016; 17: 689-701.

37. Patil N. Study of spontaneous bacterial peritonitis in cirrhosis of liver with ascites with special reference to serial ascitic fluid cell count as prognostic marker. MD dissertation, Department of General Medicine, Bangalore medical college, Rajif Ghandi University, Bangalore, 2008. 